\title{
Toxic effects of potassium permanganate on photosystem II activity of cyanobacteria Microcystis aeruginosa
}

\author{
L. $\mathrm{LI}^{*, * *+}$, X.L. PAN ${ }^{*}$, and G.J. MU** \\ State Key Laboratory of Desert and Oasis Ecology, Xinjiang Institute of Ecology and Geography, Chinese Academy \\ of Sciences, Urumqi 830011, China* \\ Cele National Station of Observation and Research for Desert-Grassland Ecosystems, Cele 848300, China**
}

\begin{abstract}
Effects of potassium permanganate $\left(\mathrm{KMnO}_{4}\right)$ on PSII of Mycrocystis aeruginosa were investigated by measuring the chlorophyll fluorescence in vivo. $\mathrm{KMnO}_{4}$ exposure reduced the rate of oxygen evolution and cell growth. High concentration of $\mathrm{KMnO}_{4}\left(10 \mathrm{mg} \mathrm{L}{ }^{-1}\right)$ decreased the fast phase and increased the slow phase of $\mathrm{Q}_{\mathrm{A}}^{-}$reoxidation kinetics. Electron transport after $\mathrm{Q}_{\mathrm{A}}$ was blocked, resulting in a considerable amount of $\mathrm{Q}_{\mathrm{A}}^{-}$reoxidation being performed via $\mathrm{S}_{2}\left(\mathrm{Q}_{\mathrm{A}} \mathrm{Q}_{\mathrm{B}}\right)^{-}$charge recombination. $\mathrm{KMnO}_{4}$ decreased the density of the active photosynthetic reaction centers and the maximum quantum yield for primary photochemistry and inhibited electron transport, which resulted in a decline of the performance of PSII activity and caused an increase in dissipated energy flux per reaction center and antenna size. Our results suggest that both the donor side and the acceptor on the phase of $\mathrm{Q}_{\mathrm{A}}^{-}$to $\mathrm{Q}_{\mathrm{B}}$ to $\mathrm{PQ}$ of PSII in M. aeruginosa were targets of $\mathrm{KMnO}_{4}$ toxicity.
\end{abstract}

Additional key words: fluorescence relaxation kinetics; inactive reaction center; S-state test.

\section{Introduction}

Cyanobacterial blooms have occurred in various water sources and are a global problem (de Figueiredo et al. 2004). Cyanobacteria rapidly increase in cell concentration and produce dissolved algal organic matter (Zhang et al. 2010), which causes serious water-quality issues, such as oxygen depletion, odors, and toxins in the drinking water supply. Microcystis aeruginosa is one of the most harmful cyanobacteria, which can introduce bad tastes and odors into the water, in addition to a wide range of toxins (Načeradská et al. 2017). Microcystin, a toxic metabolite secreted by $M$. aeruginosa, was reported to be associated with a series of health risks (Zhou et al. 2016). Therefore, in recent years, increasing research has focused on the regulation and removal of $M$. aeruginosa from water (Fujii et al. 2014, Geada et al. 2017, Načeradská et al. 2017).

Potassium permanganate is a chemical compound widely used in aquaculture for the control and removal of parasites (França et al. 2011) and in the prevention of diseases caused by bacteria and fungi (Subramanya et al. 2018). Moreover, $\mathrm{KMnO}_{4}$ is often used as a preoxidant to improve algae removal and as an algaecide to inactivate algae in the drinking water treatment industry (Chen and Yeh 2005, Rodríguez et al. 2008). $\mathrm{KMnO}_{4}$ has also been shown to be able to degrade toxins by producing physiological stress within the algae cell (Lam et al. 1995). Previous reports have shown that $\mathrm{KMnO}_{4}$ can damage the cell membrane, impair cellular integrity (Fan et al. 2013), inhibit the production of pigments (Al-Hussieny et al. 2017), and destroy the photosynthetic apparatus (Ou et al. 2012).

Photosystem II (PSII) is an important part of photosynthetic apparatus and is thought to be the primary component that is inhibited by a wide range of environmental stresses (Jiang et al. 2008). PSII consists of complicated and delicate processes, including oxygen evolution, antenna capture, and electron delivery. Any variation in the target sites can easily disrupt the transfer of energy and activity of the system. The donor-side capacity of PSII, especially oxygen-evolving complex (OEC), is the most susceptible component of PSII to heat stress, which causes the inhibition of electron donation to the secondary electron donor, the tyrosine $\mathrm{Z}\left(\mathrm{Y}_{\mathrm{Z}}\right)$ under

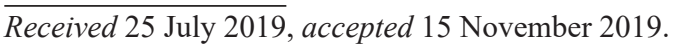

${ }^{+}$Corresponding author; e-mail: li ly@ms.xjb.ac.cn

Abbreviations: $\mathrm{ABS} / \mathrm{RC}, \mathrm{TR}_{0} / \mathrm{RC}, \mathrm{ET}_{0} / \mathrm{RC}, \mathrm{DI}_{0} / \mathrm{RC}-$ absorption, trapped, electron transport and dissipated energy flux from the antenna per reaction center, respectively; $\mathrm{F}_{\mathrm{v}}$ - the maximal variable fluorescence; OEC - oxygen-evolving complex; $\mathrm{P}_{680}-$ primary $_{\text {electron }}$ donor of PSII; $\mathrm{PI}_{\mathrm{abs}}$ - performance index; $\mathrm{PQ}$ - plastoquinone; $\mathrm{RC}$ - reaction center; $\mathrm{RC} / \mathrm{CS}_{0}-$ amount of active $\mathrm{PSII}$ reaction centers per cross section; $\mathrm{S}_{2}\left(\mathrm{Q}_{\mathrm{A}} \mathrm{Q}_{\mathrm{B}}\right)-\mathrm{Q}_{\mathrm{A}} \mathrm{Q}_{\mathrm{B}}{ }^{-}$state with the $\mathrm{S}_{2}$ state of the water-oxidizing complex; $\varphi_{\mathrm{P} 0}, \varphi_{\mathrm{E} 0}$, $\varphi_{\mathrm{D} 0}-\mathrm{quantum}$ yields of electron transport in PSII reaction center to $\mathrm{Q}_{\mathrm{A}}$, from $\mathrm{Q}_{\mathrm{A}}^{-}$to plastoquinone and in energy dissipation, respectively; $\psi_{0}-$ probability that the electron reaches electron carriers after $\mathrm{Q}_{\mathrm{A}}^{-}$.

Acknowledgements: The work was supported by National Natural Science Foundation of China (41671486, 41271494).
} 
high temperature (Pshybytko et al. 2008, Xu et al. 2014). $\mathrm{Mg}$ and $\mathrm{Ca}$ deficiency was found to produce the specific decrease in electron donation by OEC (Kalaji et al. 2014). Electron transfer after the primary electron acceptor $\mathrm{Q}_{\mathrm{A}}^{-}$ on the acceptor side of PSII is known to be inhibited in the presence of 3-(3,4-dichlorophenyl)-1,1-dimethylurea (DCMU) (Strasser et al. 2004). The analysis of metalinduced alterations in the fluorescence parameters of coral symbionts suggested that the primary targets of metal $(\mathrm{Cu}$, $\mathrm{Zn}, \mathrm{Cd}$, and $\mathrm{Pb}$ ) toxicity were the processes downstream of PSII rather than the photochemistry of PSII (Kuzminov et al. 2013). Lead was shown to induce an alteration of antenna heterogeneity and increase $\mathrm{Q}_{\mathrm{B}}$ nonreducing reaction centers (Dao and Beardall 2016). Generally, both the donor and acceptor sides in PSII have the potential to be inhibited by a wide range of chemicals (Jiang et al. 2008, Ou et al. 2012, Wang et al. 2012) and some environmental factors (Jedmowski et al. 2014, Li et al. 2014).

PSII is extremely sensitive, and, as such, oxidative stress can easily disturb electron transfer and energy allocation, destroying the photosynthetic apparatuses (Zhang et al. 2019). Cyanobacteria are autotrophic microorganisms that occupy the lower trophic levels within the food chain. Photosynthesis is the principal mode of energy metabolism in cyanobacteria, similar to plants and algae. Qiao et al. (2017) reported that $\mathrm{KMnO}_{4}$ oxidation destroys the photosynthetic systems in $M$. aeruginosa, inhibiting energy transfer and trapping the capacity of PSII, which was measured by the stable chlorophyll (Chl) $a$ fluorescence. However, little is known about the target sites and intrinsic mechanisms of the photosynthetic inactivation induced by $\mathrm{KMnO}_{4}$. This study investigated the effects of $\mathrm{KMnO}_{4}$ on the activity of PSII, including oxygen evolution, fast-rise curves, and $\mathrm{Q}_{\mathrm{A}}{ }^{-}$reoxidation kinetics, in $M$. aeruginosa by in vivo $\mathrm{Chl} a$ fluorescence transient measurements to determine the target sites of $\mathrm{KMnO}_{4}$.

\section{Materials and methods}

Cultivation and treatment of cyanobacteria: $M$. aeruginosa (FACHB-905; Fresh Water Algae Culture Collection of the Institute of Hydrobiology, Chinese Academy of Sciences) was cultured in BG-11 growth medium. Exponentially grown cells were diluted with fresh medium to achieve test samples at approx. $5 \mu \mathrm{g}(\mathrm{Chl} a) \mathrm{mL}^{-1}$ for fluorescence measurement and cultured in $10 \times 10 \mathrm{~mm}$ plastic cuvettes at a volume of $3.5 \mathrm{~mL}$ each. Analytical grade potassium permanganate $\left(\mathrm{KMnO}_{4}\right)$ was prepared and diluted to the desired concentrations; $0.5 \mathrm{~mL}$ of deionized water or $\mathrm{KMnO}_{4}$ at different concentrations was added to the sample cuvettes to achieve the final chemical concentrations of $0,0.1,1,5$, and $10 \mathrm{mg} \mathrm{L}^{-1}$. A sample without $\mathrm{KMnO}_{4}$ was used as the control. All samples were cultured at $25^{\circ} \mathrm{C}$ with the illumination at approximately $25 \mu \mathrm{mol}$ (photon) $\mathrm{m}^{-2} \mathrm{~s}^{-1}$ with a 12-h light-dark cycle. The growth of $M$. aeruginosa cells was determined by measuring the optical density at $680 \mathrm{~nm}\left(\mathrm{OD}_{680}\right)$ with a spectrophotometer (UV2800, Unico, Shanghai, China) after incubation with $\mathrm{KMnO}_{4}$ for $12 \mathrm{~h}$.
Oxygen evolution: Cells were harvested during the exponential growth phase. The rate of oxygen evolution was measured at $25^{\circ} \mathrm{C}$ using a Clark-type oxygen electrode (Oxygraph, Hansatech Instruments Ltd., King's Lynn, Norfolk, England). Three $\mathrm{mL}$ of the sample were added into the reaction cuvette for $5 \mathrm{~min}$ with the illumination at about $500 \mu \mathrm{mol}\left(\right.$ photon) $\mathrm{m}^{-2} \mathrm{~s}^{-1}$.

Chl fluorescence: All the samples were dark-adapted for $1 \mathrm{~min}$ before each test. Chl fluorescence measurements were recorded using a dual modulation kinetic fluorometer FL 3500 (Photon System Instruments, Czech Republic) $12 \mathrm{~h}$ after the treatment.

A polyphasic fluorescence rise curve was found when dark-adapted oxygenic organisms were illuminated with high-intensity actinic light. The polyphasic fluorescence induction curve includes four steps from 'origin' $(\mathrm{O})$ through two 'inflections' ( $\mathrm{J}$ and $\mathrm{I})$, and then to a 'peak' fluorescence level (P). The following data were directly obtained from the fast-rise kinetic curves: $F_{0}$, the initial fluorescence at $20 \mu \mathrm{s} ; \mathrm{F}_{300 \mu \mathrm{s}}, \mathrm{F}_{\mathrm{J}}$, and $\mathrm{F}_{\mathrm{I}}$ were the fluorescence intensities at $300 \mu \mathrm{s}, 2 \mathrm{~ms}$ (J-step), and $30 \mathrm{~ms}$ (I-step); $\mathrm{F}_{\mathrm{m}}$, the maximum fluorescence at P-step. Selected parameters were calculated from the above original data according to JIP-test (see Appendix, Strasser et al. 2004).

Analysis of the fluorescence relaxation kinetics attributed to forward and back electron transfer was performed according to Vass et al. (1999). The $\mathrm{Q}_{\mathrm{A}}^{-}$reoxidation kinetics were recorded after a single-turnover flash with the duration of $30 \mu \mathrm{s}$ and intensity of 2,500 $\mu \mathrm{mol}$ (photon) $\mathrm{m}^{-2} \mathrm{~s}^{-1}$ in the $200-\mu \mathrm{s}$ to $60-\mathrm{ms}$ time range. The $\mathrm{Q}_{\mathrm{A}}^{-}$reoxidation kinetics data were collected with eight data points per decade. In order to calculate their half-times of decay, the kinetics curves were fitted to the following threecomponent exponential function according to Vass et al. (1999):

$F(t)-F_{0}=A_{1} \exp \left(-t / T_{1}\right)+A_{2} \exp \left(-t / T_{2}\right)+A_{3} \exp \left(-t / T_{3}\right)$

where $\mathrm{F}(\mathrm{t})$ is the variable fluorescence yield at time $\mathrm{t} ; \mathrm{F}_{0}$ is the fluorescence level before the flash; $A_{1}, A_{2}$, and $A_{3}$ are the amplitudes of the fluorescence relaxation phase; $T_{1}, T_{2}$, and $\mathrm{T}_{3}$ are the rate constants.

The S-state test was carried out to determine the contribution of inactive PSII reaction centers $\left(\right.$ PSII $\left._{X}\right)$. The OEC generates oxygen after a series of oxidations through four intermediate states $\left(\mathrm{S}_{0} \rightarrow \mathrm{S}_{4}\right)$. The $\mathrm{S}$-state test discriminates the four states by short actinic light flashes. PSII $_{X}$ centers are estimated by the difference between the fluorescence level after the fourth flash and $\mathrm{F}_{0}$ because the fluorescence decay after the fourth flash is controlled almost entirely by inactive centers (Lavergne and Leci 1993). The proportion of $\mathrm{PSII}_{\mathrm{X}}$ were calculated as $100 \times\left(\mathrm{F}_{4} / \mathrm{F}_{0}-1\right)$, where $\mathrm{F}_{4}$ is the fluorescence level $110 \mathrm{~ms}$ after the fourth flash (Li et al. 2010).

Statistical analysis: All of the treatments were repeated three times. A one-way analysis of variance (ANOVA) was performed to compare the mean differences between the 
$\mathrm{KMnO}_{4}$ treatment and the control. The values of $\mathrm{PSII}_{\mathrm{X}}$ were arcsine transformed before statistical analysis to ensure homogeneity of variance. Post Hoc Tests used Student-Newman-Keuls test $(S-N-K$ test $)$ at $5 \%$ level. The statistical analysis was performed using SPSS program (13.0).

\section{Results}

Growth and oxygen evolution: The growth of $M$. aeruginosa under different concentrations of $\mathrm{KMnO}_{4}$ was measured by the $\mathrm{OD}_{680}$ (Fig. $1 A$ ). The $\mathrm{OD}_{680}$ of the cell suspension decreased significantly as the concentration of $\mathrm{KMnO}_{4}$ increased. A low concentration of $\mathrm{KMnO}_{4}(0.01$ $\mathrm{mg} \mathrm{L}^{-1}$ ) had no effect on cell growth. However, when the $\mathrm{KMnO}_{4}$ concentration exceeded $0.1 \mathrm{mg} \mathrm{L}^{-1}$, the growth of $M$. aeruginosa was inhibited. The $\mathrm{OD}_{680}$ of the culture treated with $10 \mathrm{mg} \mathrm{L}^{-1}$ of $\mathrm{KMnO}_{4}$ was $17 \%$ lower than the $\mathrm{OD}_{680}$ of the control culture.

The photosynthetic oxygen evolution of $M$. aeruginosa was also significantly inhibited by $\mathrm{KMnO}_{4}$ at 12 -h posttreatment. The oxygen-evolution rate decreased as the $\mathrm{KMnO}_{4}$ concentration increased, showing a negative linear relation. The value was almost $50 \%$ of the control in cultures treated with $10 \mathrm{mg} \mathrm{L}^{-1}$ of $\mathrm{KMnO}_{4}$ for $12 \mathrm{~h}$ (Fig. 1B).

Fast fluorescence rise: The effects of $\mathrm{KMnO}_{4}$ on the fastrise fluorescence of $M$. aeruginosa were remarkably

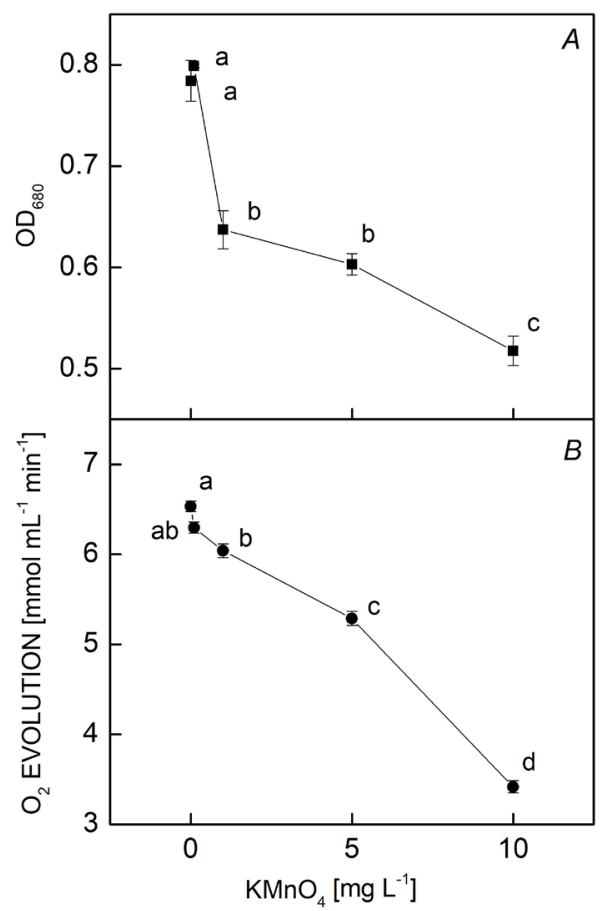

Fig. 1. The $\mathrm{OD}_{680}(A)$ and photosynthetic oxygen evolution $(B)$ of Microcystis aeruginosa treated with different concentrations of $\mathrm{KMnO}_{4}$ for $12 \mathrm{~h}$. Values represent the mean $\pm \mathrm{SE}$ of five independent measurements. Bars indicate standard errors. Different letters show significant difference between treatments $(p=0.05)$.

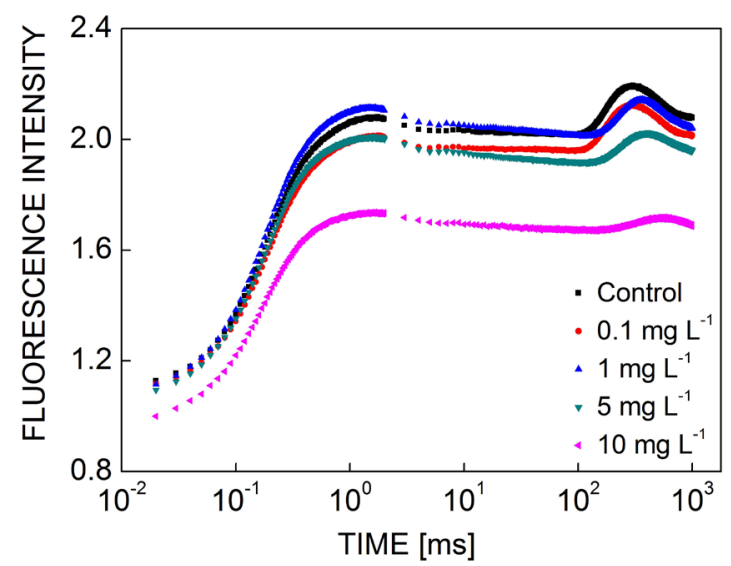

Fig. 2. The fluorescence transient of the Microcystis aeruginosa control and $\mathrm{KMnO}_{4}$ groups $\left(0.1,1,5\right.$, and $\left.10 \mathrm{mg} \mathrm{L}^{-1}\right)$ after $12 \mathrm{~h}$ of treatment. Each value is the mean of three replicates. Before the measurements, all samples were dark-adapted for $1 \mathrm{~min}$. The $x$-axis was plotted on a logarithmic time scale $(0.01 \mathrm{~ms}$ to $1 \mathrm{~s})$.

concentration-dependent (Fig. 2). The fast-rise fluorescence curves were gradually paralleled by a decrease in photosynthesis; however, the J-P phase had a flat trend due to the decline of $\mathrm{F}_{\mathrm{J}}$ and $\mathrm{F}_{\mathrm{m}}$ with the increasing $\mathrm{KMnO}_{4}$ concentration. The curve at $10 \mathrm{mg}\left(\mathrm{KMnO}_{4}\right) \mathrm{L}^{-1}$ treatment decreased rapidly from $\mathrm{F}_{0}$ to $\mathrm{F}_{\mathrm{m}}$, indicating a significant decrease as compared to other curves.

A series of parameters derived from the analysis of $\mathrm{KMnO}_{4}$ on $M$. aeruginosa cultures via the JIP test were displayed as a percentage of the control $M$. aeruginosa culture (Fig. 3). The $\mathrm{KMnO}_{4}$ treatments resulted in a decrease of $\mathrm{F}_{\mathrm{v}}, \mathrm{RC} / \mathrm{CS}_{0}, \varphi_{\mathrm{E} 0}, \psi_{0}, \mathrm{PI}_{\mathrm{abs}}$, and $\mathrm{ET}_{0} / \mathrm{RC}$, and an increase in $\varphi_{\mathrm{D} 0}, \mathrm{ABS} / \mathrm{RC}$, and $\mathrm{DI}_{0} / \mathrm{RC}$. The $\varphi_{\mathrm{P} 0}$ and $\mathrm{TR}_{0} / \mathrm{RC}$ did not show a significant difference between the $\mathrm{KMnO}_{4}$ treatments and control. A high concentration of $\mathrm{KMnO}_{4}$ $\left(>1 \mathrm{mg} \mathrm{L^{-1 }}\right.$ ) dramatically inhibited $\mathrm{PI}_{\mathrm{abs}}, \varphi_{\mathrm{E} 0}, \psi_{0}$, and $\mathrm{ET}_{0} / \mathrm{RC}$. The $10 \mathrm{mg}\left(\mathrm{KMnO}_{4}\right) \mathrm{L}^{-1}$-treated group displayed $\mathrm{PI}_{\mathrm{abs}}, \varphi_{\mathrm{E} 0}, \psi_{0}$, and $\mathrm{ET}_{0} / \mathrm{RC}$ values that were 3.1, 4.6, 5.2, and $5.5 \%$ of the control, respectively.

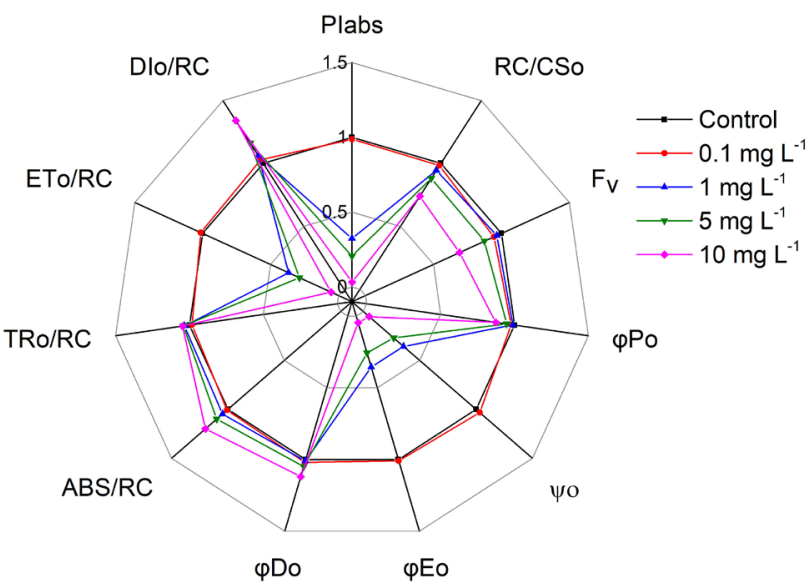

Fig. 3. A radar plot depicting changes in chlorophyll $a$ fluorescence transient parameters in Microcystis aeruginosa after treating with different $\mathrm{KMnO}_{4}$ concentrations for $12 \mathrm{~h}$. Data show the mean of three replicates. 


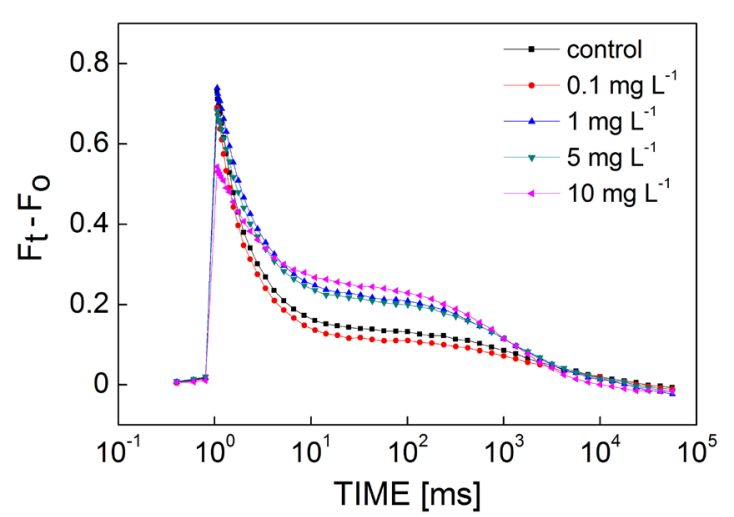

Fig. 4. The $\mathrm{Q}_{\mathrm{A}}^{-}$reoxidation of Microcystis aeruginosa in the single flash after treatment with different $\mathrm{KMnO}_{4}$ concentrations for $12 \mathrm{~h}$. Each value is the mean of three replicates. The $x$-axis was plotted on a logarithmic time scale.

$\mathbf{Q}_{\mathrm{A}}^{-}$reoxidation kinetics: The $\mathrm{Q}_{\mathrm{A}}^{-}$reoxidation kinetic curves (Fig. 4) showed the changes in the fluorescence decay of $M$. aeruginosa after a single-turnover flash after treatment with various $\mathrm{KMnO}_{4}$ concentrations for $12 \mathrm{~h}$. The amplitude of the $\mathrm{F}_{\mathrm{v}}$ decreased as the concentration of $\mathrm{KMnO}_{4}$ increased, but the decay trends retarded. The $\mathrm{Q}_{\mathrm{A}}{ }^{-}$ reoxidation kinetic curves were fitted by the triexponential equation. Related parameters were obtained and are exhibited in Table 1. The reoxidation kinetics of both the control and $\mathrm{KMnO}_{4}$-treated samples were dominated by the fast phase (63.1-91.7\%).

The $\mathrm{Q}_{\mathrm{A}}{ }^{-}$reoxidation was not affected by low $\mathrm{KMnO}_{4}$ concentrations below $0.1 \mathrm{mg} \mathrm{L}^{-1}$. However, a slight rise in the fast phase and a slight decline in the slow phase were observed at $0.1 \mathrm{mg}\left(\mathrm{KMnO}_{4}\right) \mathrm{L}^{-1}$ as compared to the control. High concentrations of $\mathrm{KMnO}_{4}\left(>0.1 \mathrm{mg} \mathrm{L}^{-1}\right)$ caused the fast phase to decrease significantly and the slow phase to increase significantly. At $10 \mathrm{mg}\left(\mathrm{KMnO}_{4}\right) \mathrm{L}^{-1}$, the fast phase decreased by $26.2 \%$, while the slow phase increased by $476 \%$, as compared with the control. Compared to the other phases, the amplitude of the middle phase showed a slight change but was not significantly different between the control and $\mathrm{KMnO}_{4}$-treatment groups (Table. 1).

The time constant of the fast phase $\left(\mathrm{T}_{1}\right)$ significantly increased as the $\mathrm{KMnO}_{4}$ concentration increased, and the value for $10 \mathrm{mg}\left(\mathrm{KMnO}_{4}\right) \mathrm{L}^{-1}$ was 2.4 times that of the control. Treatment with $10 \mathrm{mg}\left(\mathrm{KMnO}_{4}\right) \mathrm{L}^{-1}$ increased significantly at the time constant of the middle phase $\left(\mathrm{T}_{2}\right)$, but the other $\mathrm{KMnO}_{4}$ treatments had no effect on $\mathrm{T}_{2}$. The time constant of the slow phase $\left(\mathrm{T}_{3}\right)$ was not significantly different between the control and $\mathrm{KMnO}_{4}$ treatment groups.

Inactive PSII (PSII $)$ centers: The fluorescence decay induced by a series of single-turnover flashes can be exhibited through the performance of PSII RCs. High concentrations of $\mathrm{KMnO}_{4}\left(>1 \mathrm{mg} \mathrm{L}{ }^{-1}\right)$ increased the fluorescence intensity in the fourth flash (Fig. 5A). The number of PSII $_{\mathrm{X}}$ centers increased significantly as the $\mathrm{KMnO}_{4}$ concentration increased (Fig. 5B). The proportion of $\mathrm{PSII}_{\mathrm{X}}$ centers was $13.7 \%$ in the control and increased to 24.2 and $23.6 \%$ in 1 and $5 \mathrm{mg}\left(\mathrm{KMnO}_{4}\right) \mathrm{L}^{-1}$ treated groups, respectively, despite a slight drop with $0.1 \mathrm{mg}\left(\mathrm{KMnO}_{4}\right) \mathrm{L}^{-1}$ treatment. When the cells were incubated with $10 \mathrm{mg}\left(\mathrm{KMnO}_{4}\right) \mathrm{L}^{-1}$, the percentage of $\mathrm{PSII}_{\mathrm{X}}$ centers was 2.3 times (32.1\%) that of the control.

\section{Discussion}

In the present study, we demonstrated that $\mathrm{KMnO}_{4}$ inhibits the growth, photosynthetic oxygen evolution, and PSII activity of $M$. aeruginosa. These responses were derived from the function of the donor and acceptor side of PSII by a series of in vivo Chl $a$ fluorescence tests.

The cell concentration of $M$. aeruginosa decreased as the $\mathrm{KMnO}_{4}$ concentration increased. Furthermore, cell growth was significantly inhibited by high $\left(>0.1 \mathrm{mg} \mathrm{L}^{-1}\right)$ $\mathrm{KMnO}_{4}$ concentrations, whereas low concentrations had no effect on cell growth. $M$. aeruginosa showed tolerance to low concentrations of $\mathrm{KMnO}_{4}$, which was consistent with previous findings regarding the exposure of $M$. aeruginosa to arsenic (Wang et al. 2012) and N-phenyl-1naphthylamine (Cheng et al. 2017).

Oxygen evolution was more sensitive to $\mathrm{KMnO}_{4}$ treatment than cell growth and PSII activity. The value of the OEC was reduced almost by half, but the cell suspension concentration decreased only $17 \%$ compared to the control after $12 \mathrm{~h}$ of $10 \mathrm{mg}\left(\mathrm{KMnO}_{4}\right) \mathrm{L}^{-1}$ treatment, which is consistent with some reports regarding herbicides (Wang et al. 2012). This implies that the OEC is a sensitive target to $\mathrm{KMnO}_{4}$ exposure. Oxygen evolution is closely associated with photosynthesis, particularly proton gradient, ATP synthesis, and electron transport processes (Zhang et al. 2019). Therefore, negative effects

Table $1 . \mathrm{Q}_{\mathrm{A}}^{-}$reoxidation of fluorescence decay kinetics of Microcystis aeruginosa cells after $12 \mathrm{~h}$ of $\mathrm{KMnO}_{4}$ treatments. $\mathrm{A}_{1}, \mathrm{~A}_{2}$, and $\mathrm{A}_{3}$ were the amplitudes, and $\mathrm{T}_{1}, \mathrm{~T}_{2}$, and $\mathrm{T}_{3}$ were the time constants. Data were means $\pm \mathrm{SE}(n=3)$. Different letters show significant difference $(p=0.05)$.

\begin{tabular}{|c|c|c|c|c|c|c|}
\hline \multirow[t]{2}{*}{$\mathrm{KMnO}_{4}\left[\mathrm{mg} \mathrm{L}^{-1}\right]$} & \multicolumn{2}{|l|}{ Fast phase } & \multicolumn{2}{|l|}{ Middle phase } & \multicolumn{2}{|l|}{ Slow phase } \\
\hline & $\mathrm{A}_{1}[\%]$ & $\mathrm{T}_{1}[\mu \mathrm{s}]$ & $\mathrm{A}_{2}[\%]$ & $\mathrm{T}_{2}[\mathrm{~ms}]$ & $\mathrm{A}_{3}[\%]$ & $\mathrm{T}_{3}[\mathrm{~s}]$ \\
\hline 0 & $85.5 \pm 0.81^{\mathrm{a}}$ & $567 \pm 20$ & $9.92 \pm 0.27$ & $4.15 \pm 0.21$ & $4.56 \pm 0.59^{\mathrm{a}}$ & $2.51 \pm 0.23$ \\
\hline 0.1 & $86.7 \pm 0.97^{\mathrm{a}}$ & $536 \pm 17$ & $9.63 \pm 0.49$ & $4.11 \pm 0.10$ & $3.70 \pm 0.50^{\mathrm{a}}$ & $2.94 \pm 0.21$ \\
\hline 1 & $75.8 \pm 1.80^{\mathrm{b}}$ & $793 \pm 42$ & $11.60 \pm 0.16$ & $5.82 \pm 0.42$ & $12.56 \pm 1.91^{\mathrm{b}}$ & $1.78 \pm 0.06$ \\
\hline 5 & $74.2 \pm 2.04^{b}$ & $817 \pm 22$ & $12.45 \pm 0.70$ & $5.80 \pm 0.22$ & $13.32 \pm 1.36^{\mathrm{b}}$ & $1.92 \pm 0.10$ \\
\hline 10 & $63.1 \pm 0.98^{c}$ & $1,364 \pm 130$ & $10.53 \pm 1.51$ & $113.77 \pm 99.37$ & $26.34 \pm 1.92^{c}$ & $1.90 \pm 0.21$ \\
\hline
\end{tabular}




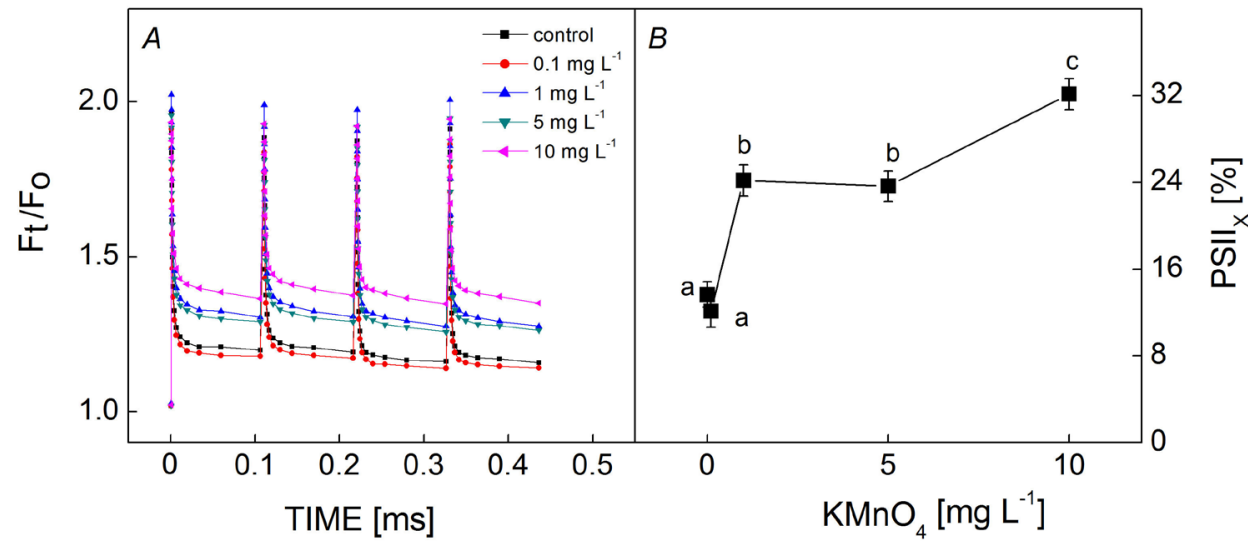

Fig. 5. The S-state $(A)$ and percentage of PIIx (B) in Microcystis aeruginosa after treatment with different $\mathrm{KMnO}_{4}$ concentrations for $12 \mathrm{~h}$. Each value is the mean of three replicates. Bars indicate standard error. Different letters show significant difference $(p=0.05)$. after $\mathrm{KMnO}_{4}$ exposure indicated that high concentrations of $\mathrm{KMnO}_{4}$ impaired not only PSII but also other parts of photosynthetic apparatus.

Chl $a$ fluorescence emitted by PSII can serve as a probe to monitor the steps of excitation energy transformation (Strasser 1997). On the fast-rise fluorescence curves, $\mathrm{KMnO}_{4}$ remarkably decreased the fluorescence intensity at J-I-P steps. This decrease was explained as the inhibition of the electron transport at the donor side of PSII, which resulted in the accumulation of $\mathrm{P}_{680}{ }^{+}$(Govindjee 1995, Wang et al. 2012). This was confirmed by the inhibitory effects of $\mathrm{KMnO}_{4}$ on oxygen evolution on the donor side of PSII, which was due to the functional deregulation of the water-splitting system (Strasser 1997). $\mathrm{KMnO}_{4}$ also decreased $\mathrm{RC} / \mathrm{CS}_{0}$, which was in accordance with the increase of $\mathrm{PSII}_{X}$ centers. The decrease in $\mathrm{RC} / \mathrm{CS}_{0}$ indicated the change of $\mathrm{Q}_{\mathrm{A}}$-reducing PSII RCs, which resulted in the inactivation of RCs or the formation of non- $\mathrm{Q}_{\mathrm{A}}$-reducing RCs (Strasser et al. 2004). Thus, the increase of ABS/RC may result from the decrease of $\mathrm{RC} / \mathrm{CS}_{0}$, which does not mean an increase in the antenna size of PSII RC of LHC complexes but an increase in the apparent antenna size (Strasser et al. 2004). More energy was dissipated due to the increased inactivation of RCs, which was supported by the increase in $\mathrm{DI}_{0} / \mathrm{RC}$ (Markou et al. 2017).

The JIP test analysis also showed that $\mathrm{KMnO}_{4}$ inhibited the electron transport of $M$. aeruginosa on the acceptor side. Decreased $F_{v}$ resulted from decreased $F_{m}$ as compared to $\mathrm{F}_{0}$, which indicated inhibition of the electron transport on the acceptor side after $\mathrm{Q}_{\mathrm{A}}$ (Jiang et al. 2008). This was confirmed by decreased $\varphi_{\mathrm{E} 0}$ and $\psi_{0}$ values. The increased $\varphi_{\mathrm{D} 0}$ and $\mathrm{DI}_{0} / \mathrm{RC}$ resulted in more dissipated energy and a substantial decrease in the $\mathrm{PI}_{\mathrm{abs}}$. Indeed, electron transport on the acceptor side has been shown to be inhibited by various types of stress, such as heavy metals (Pan et al. 2009a), antibiotics (Pan et al. 2009b), and herbicides (Eullaffroy et al. 2009).

$\mathrm{Q}_{\mathrm{A}}{ }^{-}$reoxidation kinetics can be used to test both the donor- and the acceptor-side reactions of PSII (Volgusheva et al. 2013). Dark-adapted sample produces a high fluorescence yield from $\mathrm{F}_{0}$ to $\mathrm{F}_{\mathrm{m}}$ after a saturating singleturnover flash. Subsequently, fluorescence decay within seconds exhibits the three major phases (Vass et al. 1999).
A fast phase in hundreds of microseconds indicates the $\mathrm{Q}_{\mathrm{A}}^{-}$ reoxidation by $\mathrm{Q}_{\mathrm{B}}$ in the PSII centers, where PQ is bound to the $\mathrm{Q}_{\mathrm{B}}{ }^{-}$site in the dark-adapted state. A middle phase in a few milliseconds is typical for PSII complexes, where $\mathrm{Q}_{\mathrm{A}}{ }^{-}$reoxidation is limited by the diffusion of PQ molecules to an empty $\mathrm{Q}_{\mathrm{B}}$-site. A slow phase in a few seconds to tens of seconds reflects the charge recombination from the $\mathrm{S}_{2} \mathrm{Q}_{\mathrm{A}}^{-}$state of water oxidation to the $\mathrm{S}_{1} \mathrm{Q}_{\mathrm{A}}$ state (Cao and Govindjee 1990) and can also detect the donor side of PSII (Vass et al. 1999, Mamedov et al. 2000). In the present study, it was clear that the fast phase was in the majority $(>60 \%)$ in all treatments, indicating that $\mathrm{Q}_{\mathrm{A}}^{-}$reoxidation was induced by electron transfer from $\mathrm{Q}_{\mathrm{A}}^{-}$to $\mathrm{Q}_{\mathrm{B}} / \mathrm{Q}_{\mathrm{B}}{ }^{-}$. However, the dominant activity was gradually decreased as the $\mathrm{KMnO}_{4}$ concentration increased. The slow phase, which was small in proportion, showed a rising trend as the concentration of $\mathrm{KMnO}_{4}$ increased, with a constant middle phase. Thus, higher concentrations of $\mathrm{KMnO}_{4}$ decreased the fast phase and increased the slow phase. This means that $\mathrm{KMnO}_{4}$ exposure enhanced the contribution of $\mathrm{S}_{2}\left(\mathrm{Q}_{\mathrm{A}} \mathrm{Q}_{\mathrm{B}}\right)^{-}$ charge recombination to $\mathrm{Q}_{\mathrm{A}}^{-}$reoxidation, while electron transfer from $\mathrm{Q}_{\mathrm{A}}{ }^{-}$to $\mathrm{Q}_{\mathrm{B}} / \mathrm{Q}_{\mathrm{B}}{ }^{-}$was severely blocked. $\mathrm{Q}_{\mathrm{A}}{ }^{-}$was mostly oxidized with the process. Similar responses were observed under UV-B Radiation (Volgusheva et al. 2013) and lead exposure (Dao and Beardall 2016).

$\mathrm{KMnO}_{4}$ oxidation was harmful to the oxygenic photosynthetic systems. A PSII stable fluorescence test showed that high concentrations of $\mathrm{KMnO}_{4}$ inhibited cell growth and decreased typical photosynthetic parameters, including the effective quantum yield and photosynthetic efficiency of both Anabaena spiroides (Qiao et al. 2017) and $M$. aeruginosa (Ou et al. 2012). In the present study, we investigated the effects of $\mathrm{KMnO}_{4}$ exposure on the activity of PSII by analyzing the oxygen evolution, fast fluorescence transient, $\mathrm{Q}_{\mathrm{A}}^{-}$reoxidation kinetics, and S-state test of $\mathrm{PSII}_{\mathrm{X}}$ centers. The results showed that $\mathrm{KMnO}_{4}$ exposure changed the antenna size and increased the RCs that became inactive or formed non- $\mathrm{Q}_{\mathrm{A}}$-reducing $\mathrm{RCs}$. Oxidation damaged the photosynthetic electron transport chain on the donor side, inhibiting oxygen evolution. The acceptor side, especially on the phase of $\mathrm{Q}_{\mathrm{A}}^{-}$to $\mathrm{Q}_{\mathrm{B}}$ to $\mathrm{PQ}$, was the acting site of $\mathrm{KMnO}_{4}$ oxidation, resulting in the decline of photosynthetic efficiency. 


\section{References}

Al-Hussieny A.A., Alraheem E.A., Lafta H.Y. et al.: Algae personification toxicity by GC-MASS and treatment by using material potassium permanganate in exposed basin. - Egypt. J. Petrol. 26: 835-842, 2017.

Cao J., Govindjee: Chlorophyll $a$ fluorescence transient as an indicator of active and inactive photosystem II in thylakoid membranes. - BBA-Bioenergetics 1015: 180-188, 1990.

Chen J.J., Yeh H.H.: The mechanisms of potassium permanganate on algae removal. - Water Res. 39: 4420-4428, 2005.

Cheng L., He Y., Tian Y. et al.: Comparative biotoxicity of $\mathrm{N}$-phenyl-1-naphthylamine and N-phenyl-2-naphthylamine on cyanobacteria Microcystis aeruginosa. - Chemosphere 176: 183-191, 2017

Dao L.H.T., Beardall J.: Effects of lead on two green microalgae Chlorella and Scenedesmus: photosystem II activity and heterogeneity. - Algal Res. 16: 150-159, 2016.

de Figueiredo D.R., Azeiteiro U.M., Esteves S.M. et al.: Microcystin-producing blooms - a serious global public health issue. - Ecotox. Environ. Safe. 59: 151-163, 2004.

Eullaffroy P., Frankart C., Aziz A. et al.: Energy fluxes, driving forces for photosynthesis in Lemna minor exposed to herbicides. - Aquat. Bot. 90: 172-178, 2009.

Fan J., Daly R., Hobson P. et al.: Impact of potassium permanganate on cyanobacterial cell integrity and toxin release and degradation. - Chemosphere 92: 529-534, 2013.

França J.G., Paiva M.J.T.R., Carvalho S. et al.: Toxicity of the therapeutic potassium permanganate to tilapia Oreochromis niloticus and to non-target organisms Ceriodaphnia dubia (microcrustacean cladocera) and Pseudokirchneriella subcapitata (green microalgae). - Aquaculture 322-323: 249254, 2011.

Fujii M., Dang T.C., Bligh M.W. et al.: Effect of natural organic matter on iron uptake by the freshwater cyanobacterium Microcystis aeruginosa. - Environ. Sci. Technol. 48: 365374, 2014.

Geada P., Pereira R.N., Vasconcelos V. et al.: Assessment of synergistic interactions between environmental factors on Microcystis aeruginosa growth and microcystin production. - Algal Res. 27: 235-243, 2017.

Govindjee: Sixty-three years since Kautsky: Chlorophyll a fluorescence. - Aust. J. Plant Physiol. 22: 131-160, 1995.

Jedmowski C., Bayramov S., Brüggemann W. et al.: Comparative analysis of drought stress effects on photosynthesis of Eurasian and North African genotypes of wild barley. - Photosynthetica 52: 564-573, 2014.

Jiang H.X., Chen L.S., Zheng J.G. et al.: Aluminum-induced effects on photosystem II photochemistry in Citrus leaves assessed by the chlorophyll $a$ fluorescence transient. - Tree Physiol. 28: 1863-1871, 2008.

Kalaji H.M., Oukarroum A., Alexandrov V. et al.: Identification of nutrient deficiency in maize and tomato plants by in vivo chlorophyll $a$ fluorescence measurements. - Plant Physiol. Bioch. 81: 16-25, 2014.

Kuzminov F.I., Brown C.M., Fadeev V.V., Gorbunov M.Y.: Effects of metal toxicity on photosynthetic processes in coral symbionts, Symbiodinium spp. - J. Exp. Mar. Biol. Ecol. 446: 216-227, 2013.

Lam A.K.Y., Prepas E.E., Spink D., Hrudey S.E.: Chemical control of hepatotoxic phytoplankton blooms: Implications for human health. - Water Res. 29: 1845-1854, 1995.

Lavergne J., Leci E.: Properties of inactive photosystem II centers. - Photosynth. Res. 35: 323-343, 1993.

Li L., Chen X., Zhang D.Y., Pan X.L.: Effects of insecticide acetamiprid on photosystem II (PSII) activity of Synechocystis sp.
(FACHB-898). - Pestic. Biochem. Phys. 98: 300-304, 2010.

Li X.M., Chen M.J., Li J. et al.: Effect of endophyte infection on chlorophyll $a$ fluorescence in salinity stressed rice. - Biol. Plantarum 58: 589-594, 2014.

Mamedov F., Stefansson H., Albertsson P.Å., Styring S.: Photosystem II in different parts of the thylakoid membrane: A functional comparison between different domains. Biochemistry 39: 10478-10486, 2000.

Markou G., Dao L.H.T., Muylaert K., Beardall J.: Influence of different degrees of $\mathrm{N}$ limitation on photosystem II performance and heterogeneity of Chlorella vulgaris. - Algal Res. 26: 84-92, 2017.

Načeradská J., Pivokonský M., Pivokonská L. et al:: The impact of pre-oxidation with potassium permanganate on cyanobacterial organic matter removal by coagulation. Water Res. 114: 42-49, 2017.

Ou H., Gao N., Wei C. et al.: Immediate and long-term impacts of potassium permanganate on photosynthetic activity, survival and microcystin-LR release risk of Microcystis aeruginosa.J. Hazard. Mater. 219-220: 267-275, 2012.

Pan X.L., Chen X., Zhang D.Y. et al.: Effect of chromium (VI) on photosystem II activity and heterogeneity of Synechocystis sp. (Cyanophyta): studied with in vivo chlorophyll fluorescence tests. - J. Phycol. 45: 386-394, 2009a.

Pan X.L., Zhang D.Y., Chen X. et al.: Effects of levofloxacin hydrochloride on photosystem II activity and heterogeneity of Synechocystis sp. - Chemosphere 77: 413-418, 2009 b.

Pshybytko N.L., Kruk J., Kabashnikova L.F., Strzalka K.: Function of plastoquinone in heat stress reactions of plants. BBA-Bioenergetics 1777: 1393-1399, 2008.

Qiao J., Zhang X., Lv L.: Removal of Anabaena spiroides by potassium permanganate pre-oxidation: Effect on photosynthetic capacity and molecular weight distribution. Environ. Sci. Pollut. R. 24: 24207-24213, 2017.

Rodríguez E.M., Acero J.L., Spoof L., Meriluoto J.: Oxidation of MC-LR and -RR with chlorine and potassium permanganate: Toxicity of the reaction products. - Water Res. 42: 1744-1752, 2008.

Strasser B.J.: Donor side capacity of Photosystem II probed by chlorophyll $a$ fluorescence transients. - Photosynth. Res. 52: 147-155, 1997.

Strasser R.J., Tsimilli-Michael M., Srivastava A.: Analysis of the chlorophyll $a$ fluorescence transient. - In: Papageorgiou G.C., Govindjee (ed.): Chlorophyll $a$ Fluorescence: A Signature of Photosynthesis. Advances in Photosynthesis and Respiration. Pp. 321-362. Springer, Dordrecht 2004.

Subramanya S.H., Pai V., Bairy I. et al.: Potassium permanganate cleansing is an effective sanitary method for the reduction of bacterial bioload on raw Coriandrum sativum. - BMC Res. Notes 11: 124, 2018.

Vass I., Kirilovsky D., Etienne A.L.: UV-B radiation-induced donor- and acceptor-side modifications of photosystem II in the cyanobacterium Synechocystis sp. PCC 6803. Biochemistry 38: 12786-12794, 1999.

Volgusheva A., Styring S., Mamedov F.: Increased photosystem II stability promotes $\mathrm{H}_{2}$ production in sulfur-deprived Chlamydomonas reinhardtii. - P. Natl. Acad. Sci. USA 110: 7223-7228, 2013.

Wang S., Zhang D., Pan X.: Effects of arsenic on growth and photosystem II (PSII) activity of Microcystis aeruginosa. Ecotox. Environ. Safe. 84: 104-111, 2012.

Xu H., Liu G., Liu G. et al.: Comparison of investigation methods of heat injury in grapevine (Vitis) and assessment to heat tolerance in different cultivars and species. - BMC Plant Biol. 14: 156-165, 2014.

Zhang H., Liu N., Zhao J. et al.: Disturbance of photosystem II- 
oxygen evolution complex induced the oxidative damage in Chlorella vulgaris under the stress of cetyltrimethylammonium chloride. - Chemosphere 223: 659-667, 2019.

Zhang X.J., Chen C., Ding J.Q. et al.: The 2007 water crisis in Wuxi, China: Analysis of the origin. - J. Hazard. Mater. 182:
130-135, 2010.

Zhou S., Yin H., Tang S. et al.: Physiological responses of Microcystis aeruginosa against the algicidal bacterium Pseudomonas aeruginosa. - Ecotox. Environ. Safe. 127: 214221, 2016.

Appendix. Formulae and terms used in the JIP-test for the analysis of the fluorescence transient O-J-I-P (Strasser et al. 2004).

\begin{tabular}{ll}
\hline Formulae and terms & Explanations \\
\hline $\mathrm{V}_{\mathrm{J}}=\left(\mathrm{F}_{2 \mathrm{~ms}}-\mathrm{F}_{0}\right) /\left(\mathrm{F}_{\mathrm{m}}-\mathrm{F}_{0}\right)$ & Relative variable fluorescence at the J-step \\
$\mathrm{M}_{0}=4\left(\mathrm{~F}_{300 \mu \mathrm{s}}-\mathrm{F}_{0}\right) /\left(\mathrm{F}_{\mathrm{m}}-\mathrm{F}_{0}\right)$ & Approximated initial slope of the fluorescence transient \\
$\mathrm{ABS} / \mathrm{CS}_{0}=\mathrm{F}_{0}$ & Absorption flux per $\mathrm{CS}_{0}$, approximated by $\mathrm{F}_{0}$ \\
$\mathrm{ABS} / \mathrm{RC}=\mathrm{M}_{0}\left(1 / \mathrm{V}_{\mathrm{J}}\right)\left(1 / \varphi_{\mathrm{P} 0}\right)$ & Absorption flux per $\mathrm{RC}$ \\
$\mathrm{TR}_{0} / \mathrm{RC}=\mathrm{M}_{0}\left(1 / \mathrm{V}_{\mathrm{J}}\right)$ & Trapped energy flux per RC $(\mathrm{at} \mathrm{t}=0)$ \\
$\mathrm{ET}_{0} / \mathrm{RC}=\mathrm{M}_{0}\left(1 / \mathrm{V}_{\mathrm{J}}\right) \psi_{0}$ & Electron transport flux per $\mathrm{RC}(\mathrm{at} \mathrm{t}=0)$ \\
$\mathrm{DI}_{0} / \mathrm{RC}=(\mathrm{ABS} / \mathrm{RC})-\left(\mathrm{TR}_{0} / \mathrm{RC}\right)$ & Dissipated energy flux per $\mathrm{RC}(\mathrm{at} \mathrm{t}=0)$ \\
$\psi_{0}=\mathrm{ET}_{0} / \mathrm{TR}_{0}=\left(1-\mathrm{V}_{\mathrm{J}}\right)$ & Probability (at $\mathrm{t}=0)$ that a trapped exciton moves an electron into \\
$\varphi_{\mathrm{P} 0}=\mathrm{TR}_{0} / \mathrm{ABS}=\left[1-\left(\mathrm{F}_{0} / \mathrm{F}_{\mathrm{m}}\right)\right]$ & the electron transport chain beyond $\mathrm{Q}_{\mathrm{A}}^{-}$ \\
$\varphi_{\mathrm{E} 0}=\mathrm{ET}_{0} / \mathrm{ABS}=\left[1-\left(\mathrm{F}_{0} / \mathrm{F}_{\mathrm{m}}\right)\right] \psi_{0}$ & Maximum quantum yield of primary photochemistry (at $\mathrm{t}=0)$ \\
$\varphi_{\mathrm{D} 0}=1-\varphi_{\mathrm{P} 0}=\mathrm{F}_{0} / \mathrm{F}_{\mathrm{m}}$ & Quantum yield of electron transport (at $\mathrm{t}=0)$ \\
$\mathrm{RC}_{\mathrm{CS}}=\varphi_{\mathrm{P} 0}\left(\mathrm{~V}_{\mathrm{J}} / \mathrm{M}_{0}\right)\left(\mathrm{ABS} / \mathrm{CS}_{0}\right)$ & Quantum yield (at $\mathrm{t}=0)$ of energy dissipation \\
$\mathrm{PI}_{\mathrm{abs}}=(\mathrm{RC} / \mathrm{ABS})\left[\varphi_{\mathrm{P} 0} /\left(1-\varphi_{\mathrm{P} 0}\right)\right]\left[\psi_{0} /\left(1-\psi_{0}\right)\right]$ & Density of RCs $\left(\mathrm{Q}_{\mathrm{A}}\right.$-reducing PSII reaction centers) \\
\hline
\end{tabular}

(C) The authors. This is an open access article distributed under the terms of the Creative Commons BY-NC-ND Licence. 